\author{
G O N ZALO G A L D S
}

\title{
Toma de decisiones
}

Elecciones acertadas para el éxito personal y profesional

Segunda edición

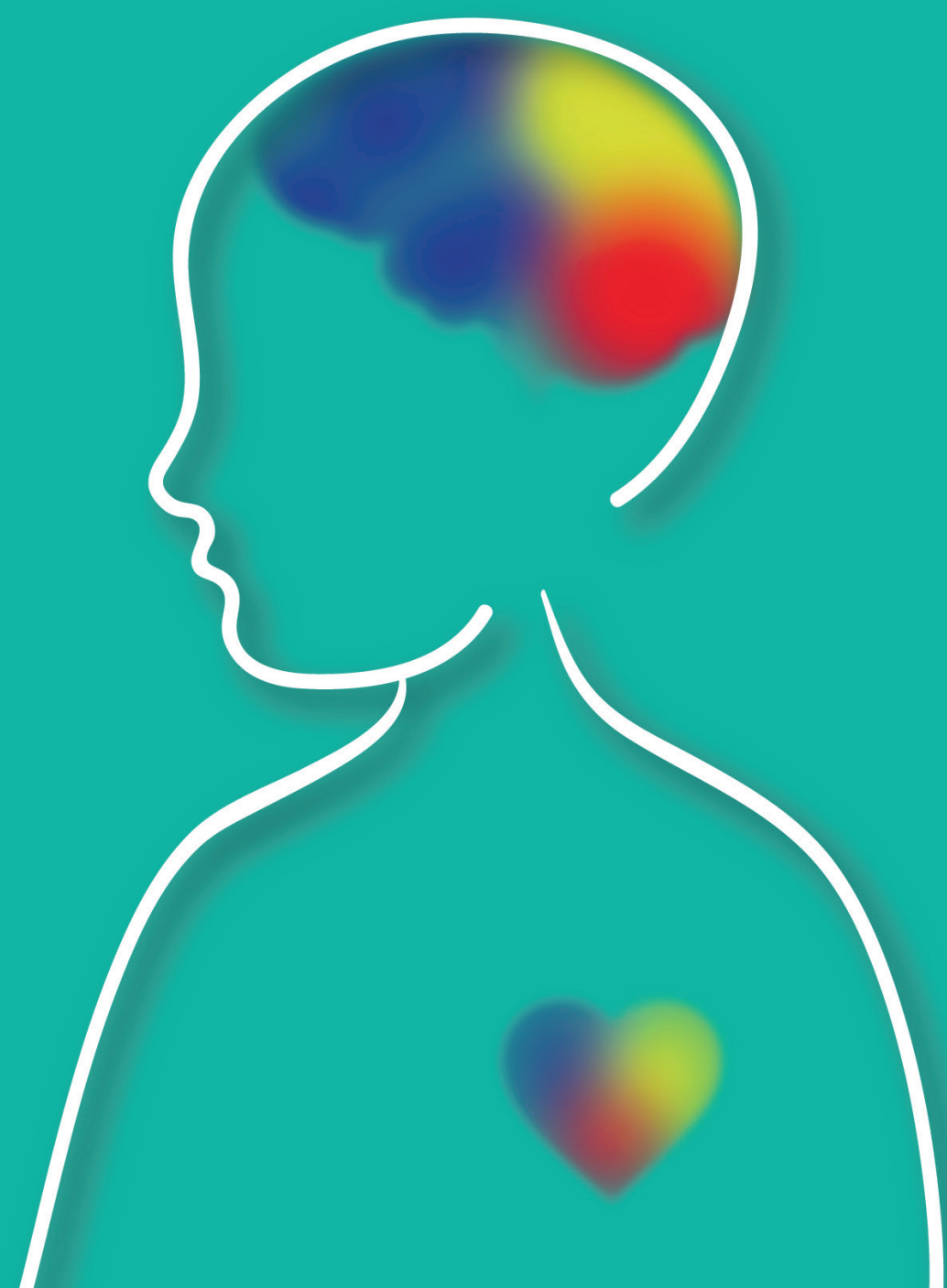




$$
\text { G O N Z A L G A L D O S }
$$

\title{
Toma de decisiones
}

Elecciones acertadas para el éxito personal y profesional

\author{
Segunda edición
}

Universidad Peruana de Ciencias Aplicadas

Lima, julio de 2015 
(C) Universidad Peruana de Ciencias Aplicadas (UPC)

Impreso en el Perú - Printed in Peru

Edición: Diana Félix

Corrección de estilo: Gabriela Vargas Philippon

Diagramación: María Victoria Vásquez

Diseño de carátula: $\quad$ María Victoria Vásquez

Editor del proyecto editorial

Universidad Peruana de Ciencias Aplicadas S. A. C.

Av. Alonso de Molina 1611, Lima 33 (Perú).

Teléf. 313-3333

www.upc.edu.pe

Primera edición: 2010

Segunda edición: 2015

Tiraje: 2000 ejemplares

Este libro se terminó de imprimir en el mes de julio de 2015 en los talleres gráficos de Industria Gráfica Cimagraf S.A.C. Pj. Santa Rosa 220, Ate Vitarte, Lima, Perú

\section{Universidad Peruana de Ciencias Aplicadas (UPC) \\ Centro de Información}

Gonzalo Galdos. Toma de decisiones.

Elecciones acertadas para el éxito personal y profesional

Lima: Universidad Peruana de Ciencias Aplicadas (UPC), 2015

ISBN: 978-612-318-030-0

TOMA DE DECISIONES / ÉXITO / RIESGO / ASPECTOS PSICOLÓGICOS

658.403 GALD 2015

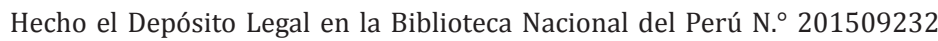

Registro de Proyecto Editorial en la Biblioteca Nacional del Perú N.ํ 31501401500744

Todos los derechos reservados. Esta publicación no puede ser reproducida, ni en todo ni en parte, ni registrada en o transmitida por un sistema de recuperación de información, en ninguna forma ni por ningún medio, sea mecánico, fotoquímico, electrónico, magnético, electroóptico, por fotocopia o cualquier otro, sin el permiso previo, por escrito, de la editorial.

El contenido de este libro es responsabilidad del autor y no refleja necesariamente la opinión de los editores. 
A mi familia,

Isabel, Rodrigo y Sergio

A mi socia y gran colaboradora, Mimi Telaya

A mis mentores, Ettore Azzaroni y Ramón Remolina Serrano

A mis alumnos 
«-Minino de Cheshire, ¿podrías decirme, por favor, qué camino debo seguir para salir de aquí?

—Eso depende en gran parte del sitio al que quieras llegar, dijo el Gato.

—No me importa mucho el sitio, dijo Alicia.

-Entonces tampoco importa mucho el camino que tomes, dijo el Gato.

-Siempre que llegue a alguna parte, añadió Alicia como explicación.

— ¡Oh, siempre llegarás a alguna parte —aseguró el Gato— si caminas lo suficiente!»

LEWIS CARROLL, Alicia en el país de las maravillas

«Decidir es el proceso de contestar varias preguntas: la primera, acerca de lo que debemos hacer; la segunda —si somos curiosos-, acerca de lo que queremos hacer y, finalmente, la tercera si somos osados-, acerca de quiénes realmente somos». 


\section{Contenido}

Presentación

Prólogo

Introducción

Modelos mentales

La adicción al corto plazo

Certeza o ceguera

La manía de postergar lo estructural

La escalera de la inferencia

La columna izquierda

La dictadura de los persuasivos

Diálogo y etiquetas

La navaja de Occam

Inteligencia y éxito

El temperamento y el riesgo 
$\begin{array}{ll}\text { El palco de los Muppets } & 73\end{array}$

$\begin{array}{ll}\text { El sendero del miedo } & 77\end{array}$

$\begin{array}{ll}\text { La era de los mortales } & 81\end{array}$

Decisiones individuales y sesgos psicológicos $\quad 85$

$\begin{array}{ll}\text { La primera impresión es la que cuenta } & 87\end{array}$

$\begin{array}{ll}\text { El sesgo de confirmación } & 91\end{array}$

La trampa del anclaje $\quad 95$

La parábola de San Petersburgo 99

$\begin{array}{ll}\text { La maldición del ganador } & 105\end{array}$

$\begin{array}{ll}\text { Decisiones en equipo y sesgos sociológicos } & 109\end{array}$

El efecto conformismo 111

$\begin{array}{ll}\text { La escalada del compromiso } & 115\end{array}$

$\begin{array}{ll}\text { Memorias del futuro } & 119\end{array}$

La rendición de cuentas 123

$\begin{array}{ll}\text { El dilema del prisionero } & 127\end{array}$

$\begin{array}{ll}\text { La tensión creativa } & 131\end{array}$

La teoría de las ventanas rotas $\quad 135$

$\begin{array}{ll}\text { El equilibrio de Nash } & 139\end{array}$

$\begin{array}{ll}\text { Arquetipos } & 143\end{array}$

$\begin{array}{ll}\text { Limitaciones para el éxito } & 145\end{array}$ 
Éxitos solo para el exitoso

Metas a la deriva

Crecer o morir

Muchos dueños o ninguno

Epílogo

165

Entrevistas 


\section{Presentación}

Con su conocida y envidiable claridad, los norteamericanos suelen distinguir entre thinkers y doers, según predominen en las personas las destrezas del pensamiento o de la acción. Gonzalo Galdos es uno de los pocos ejemplos en que esa distinción resulta inútil, pues se desenvuelve en ambas con igual soltura y eficacia.

En la vida académica y en la actividad empresarial, el autor ha sentado trayectoria de directivo y maestro, indistintamente. En su desempeño, no resulta fácil diferenciar las decisiones de las lecciones, y quien trate de hacerlo terminará convencido de la inutilidad de ese propósito.

Me tocó compartir con Gonzalo Galdos el quehacer de la gestión académica, y pude apreciar sus dotes congénitas de un realizador fundamentado: sus ideas y propuestas iban siempre presididas por la guía de un conocimiento probado o de una vivencia útil. Pero, a la vez, era un pensador experimentado: sus acciones estaban invariablemente inspiradas en la teoría más pertinente o en la intuición más inteligente.

Cuando escuchaba al autor la explicación de una situación, tuve varias veces la sensación de estar presenciando una exposición profesoral. Y, cuando me tocó participar en alguna de sus tareas docentes, creí encontrarme frente a un relator de experiencias empresariales.

Imagino que percepciones similares debemos haber compartido los lectores de sus artículos, cuando El Comercio nos regalaba la oportunidad de seguirlo también en esa faceta de docencia periodística. Los mismos que ahora $-\mathrm{y}$ junto con aquellos que tienen a través de este libro la primera 
ocasión de conocerlo- vemos complacidos la posibilidad de acceder a esas publicaciones, ordenadas y sistematizadas.

Gonzalo Galdos nos habla en las siguientes páginas de las decisiones, que son el pan de cada día en la vida de millones de personas, vida que precisamente gira en torno a tales decisiones y de cuyo acierto o desacierto depende en gran parte su éxito —o su fracaso — profesional y personal. Nada menos. El autor se ha propuesto ayudarnos a conocer cómo y por qué decidimos, para, de esta forma, ayudarnos a mejorar en esta tarea que constituye el centro cardinal de nuestra experiencia en las múltiples organizaciones entre las que nos desenvolvemos y pasamos nuestras vidas.

Las lecturas que tenemos por delante servirán, por lo tanto, de brújula y, a la vez, de hoja de ruta, de orientación y de relato. No resultará fácil distinguir cuánto hay en ellas de teoría explicada o de práctica relatada. No lo intentemos. No olvidemos que nos encontramos ante la obra de un thinkerdoer.

Luis Bustamante Belaunde Rector emérito de la Universidad Peruana de Ciencias Aplicadas (UPC) 


\section{Prólogo}

Imaginemos a uno de nuestros antepasados, hace cien mil años. Se desplaza en un paisaje que combina vegetación y espacios abiertos. Súbitamente, escucha un ruido. Debe tomar una decisión. Lo debe hacer.

Nuestro tatarabuelo imaginario podría reflexionar algo así como: «¿Será un tigre o no? Si lo es, podría ser vegetariano o quizá ya comió». Sus genes no se encuentran entre nosotros, como sí lo están aquellos que habitaron organismos que tomaban decisiones rápidamente, sobre la base de información incompleta. Los términos de la decisión no son epistemológicos, no tienen que ver con la verdad, sino con la supervivencia.

El cartesianismo imperante en la civilización occidental dejó de lado lo anterior, lo que tuvo muchas y muy importantes consecuencias positivas, pero algunas muy negativas: olvidar los límites de nuestra mente en razón de aquello para lo que evolucionó, especialmente cuando se trata de encontrar patrones y aceptar que a veces no los hay, cuando se debe estimar probabilidades y riesgos, cuando hay que pensar en horizontes temporales largos. Vale decir, cuando debemos tomar decisiones complejas en entornos en los que, contrariamente al Paleolítico, no está en juego nuestra vida y el menú de opciones es casi ilimitado.

La investigación en la irracionalidad de la mente, condición para entenderla mejor y superar sus consecuencias, comenzó en la década de 1970 con los trabajos pioneros de Kahneman y Tversky. Hoy, con Ariely y muchos más, la economía comportamental nos enseña a ser más humildes, pero aún más eficaces. 
Gonzalo Galdos contribuye con este libro a la teoría y práctica de la toma de decisiones. Lo hace combinando, como debe ser, marcos conceptuales de referencia y una larga experiencia en el trabajo con ejecutivos en contextos concretos, que plantean la realidad organizacional y empresarial de nuestro país.

Desde la introducción al epílogo, Galdos revisa, de manera sencilla al mismo tiempo que profunda, todas las formas en las que nuestra mente es nuestra peor enemiga, justamente para ofrecernos la posibilidad de que se convierta en una aliada.

Aunque tomar decisiones es un asunto especialmente complejo, lleno de recovecos desconocidos y trampas internas, en el caso de leer o no este pequeño libro que tiene la virtud de la claridad, la cosa es más bien sencilla.

¡Vale la pena!

Roberto Lerner

Psicólogo 


\section{Introducción}

Como consultor, directivo y emprendedor en diversos sectores, empresas y multinacionales y asimismo como profesor de posgrado, uno de mis objetivos principales es ayudar a jefes, colegas, subordinados y alumnos a tomar mejores decisiones. Confieso que mi estrategia, durante muchos años, fue tratar de que sean más racionales y pongan bajo control la intuición y las emociones. Después de todo, pensaba que las recientes investigaciones de cómo funciona nuestra mente apenas vislumbran la influencia de cada uno de los factores anteriormente señalados, pero, en general, seguía siendo una suerte de caja negra de imprevisibles resultados.

Durante los primeros años de mi ejercicio profesional y académico, observaba cómo la voluntad de mi audiencia por mejorar se estrellaba con fuerzas inconscientes que echaban por tierra sus deseos, y perjudicaban la calidad de sus decisiones en clase y en el trabajo. Esta frustración, tuvo finalmente consuelo cuando los últimos avances en neurociencias vinieron en nuestro auxilio, abriendo la caja negra y explicando que nuestra mente no funciona como creíamos, y que la dicotomía entre lógica y sentimiento es más compleja de lo pensado y, por tanto, todo intento de usarla en nuestras decisiones, lejos de ser pertinente, puede ser muy dañino y autodestructivo.

Los descubrimientos sobre la forma como funciona la corteza orbito prefrontal, aquella zona del cerebro donde se aloja el proceso de decisión, nos enfrentan con nuestra verdadera naturaleza y esencia: los seres humanos no somos tan racionales como pensamos, nuestras decisiones no solo están contaminadas por emociones, sentimientos y circunstancias, sino que el comando de las mismas se alterna entre el sentimiento puro, la intuición y el raciocinio puro o combinaciones desconocidas que están muy lejos de ser 
administradas conscientemente.

Este libro sistematiza una serie de artículos que he publicado, agregando la experiencia de años recientes y los aportes de varios especialistas, bajo la forma de parábolas y anécdotas que pretenden ayudar a las personas en general a tomar conciencia acerca de nuestras limitaciones como seres humanos cuando decidimos, y, además, a evaluar la relación entre riesgo y beneficio que toda decisión conlleva. Todo el tiempo estamos tomando decisiones y con ellas estamos creando o destruyendo valor en nuestras vidas. Muchas veces, la magnitud de la oportunidad obnubila nuestra mente y sacrificamos el largo plazo; por ello, es importante darles participación a las personas correctas en decisiones complejas y de gran impacto. Recordemos, sin embargo, que tomar decisiones en equipo tampoco garantiza tomar mejores decisiones: está demostrado que agrega potencial de mejora pero también complejidad y sesgos.

El objetivo del libro apunta a que tanto los profesionales, los estudiantes y las personas en general conozcan mejor cómo deciden y por qué suelen hacerlo de una forma u otra, y lograr de esa manera que ese conocimiento los ayude a mejorar día a día en sus decisiones.

Incluso, se incorporaron algunos resultados preliminares de la investigación realizada sobre cómo deciden los gerentes en el Perú, los mismos que son parte de una tesis doctoral y que aportan información explícita que, espero, los lectores la encuentren interesante y útil. Por otra parte, con toda sinceridad pienso que no me corresponde decirles a las personas qué decisiones tomar o cuánto riesgo pueden o deberían asumir con ellas; esa es una elección individual y legítima. Sin embargo, me siento responsable de ayudarles a conocer bien «cómo deciden» y a analizar la oportunidad y el riesgo involucrado en sus decisiones. En pocas palabras, a que no decidan en la ignorancia. Sobre todo, les recomiendo tener cuidado, puesto que los seres humanos, que proclamamos ser la única especie racional de las existentes, somos, después de todo, la más emocional de todas. 


\section{MODELOS MENTALES}

«Entonces, ¿qué hacemos? Cualquier cosa. Algo. Mientras que no sea no hacer nada. Si nos equivocamos, empezamos de nuevo. Probamos alguna otra cosa.

Si esperamos hasta que hayamos satisfecho todas las incertidumbres, puede ser demasiado tarde».

LEE IACOCCA 


\section{La adicción al corto plazo}

Es muy probable que en tu trabajo o en tu vida diaria te haya ocurrido que, tratando de lograr un objetivo determinado, el resultado final terminó siendo exactamente lo contrario de lo que querías, por razones que en ese momento no eran nada claras ni evidentes. Es más, mientras mayor fue tu esfuerzo o insistencia en ciertas acciones, el resultado solo empeoró.

Hace unos años, estrenaron la película El efecto mariposa, en la que al protagonista le ocurre una situación similar. Él tiene la posibilidad de regresar al pasado y realizar acciones distintas para cambiar un curso negativo de acontecimientos y, sin embargo, no hace otra cosa que empeorar los resultados para él o para alguno de sus amigos.

En ambas situaciones, tú y el protagonista de la película fueron víctimas de ciertos patrones o «arquetipos» que gobiernan las relaciones causaefecto en todos los campos de actividad humana, como las ciencias físicas y sociales, la ingeniería o la administración de empresas, que se comportan como un sistema dinámico.

Por ello, con frecuencia escuchamos reiteradas expresiones de sabiduría popular que definen y dan nombre a algunos de estos arquetipos, como «el disparo le salió por la culata», «la lavada terminó siendo más cara que la camisa», o algunas hasta más escuetas y no por ello exentas de profundidad: «fue una bola de nieve»o «entró en trompo». 
En todos los casos, los protagonistas sufrieron en carne propia los efectos de interrelaciones sutiles entre las partes y las acciones que componen cada sistema. Es evidente, después del resultado, que los afectados no fueron capaces de ver o entender todas las interacciones de un sistema y, por lo tanto, con su participación activa la situación solo empeoró.

Algunos estudiosos del fenómeno, como Chris Argyris ${ }^{1}$ y Peter M. Senge (cuyo libro, La quinta disciplina, está íntegramente dedicado al tema), explican que las razones por las cuales se producen estos patrones negativos son diversas, pero reiterativas. La primera - muy ligada a nuestra idiosincrasia - es la búsqueda de una solución rápida y fácil; la segunda es la falta de información objetiva o de conocimiento sobre cómo funciona el sistema desde una perspectiva integral y total; y la tercera y más grave ocurre cuando, a sabiendas de los efectos indeseados o negativos, en forma consciente el problema se traslada a otra parte del sistema o a otra persona («pasándola de taquito»), generándose una externalidad: la de acumular la basura debajo de la alfombra o arrojarla al río. Dicho en términos empresariales, la factura no desaparece, pero es otro el que la paga, como en la película mencionada: el protagonista en algunos intentos solucionaba su problema, pero a costa de una desgracia para sus amigos.

En un mundo complejo y con negocios cada vez más complicados, las fallas o errores sistémicos se acumulan por doquier, debido a la creciente dificultad por entender dicha complejidad y la presión por resultados a corto plazo. Por ejemplo, políticos y gobernantes que dejan situaciones insostenibles a sus sucesores, gerentes que heredan bombas de tiempo de sus predecesores, países enteros que se hacen de la vista gorda frente a problemas sin precedentes como el hambre, la miseria o el calentamiento global. Por supuesto, todos nos preguntamos por qué si estas fallas tienen un origen cierto y tienen también responsables directos, ¿cómo es posible tanta impu-

1 Cfr. Argyris y Senge 2005 «Barreras interpersonales para la adopción de decisiones», en Harvard Business Review: la toma de decisiones. Santiago de Chile: Deusto. 
nidad? La respuesta la encontramos en una característica propia del sistema: causas y efectos importantes suelen estar separados por un largo periodo, tan grande que uno puede incluso olvidar la conexión.

¿Cuándo empezó realmente la decadencia de una empresa? Pues es muy probable que fuera mucho antes de que el síntoma de las ventas bajas se hiciera evidente. ¿Cuánto tiempo tienen que esperar los padres para saber, objetivamente, si la educación impartida a un hijo fue la correcta? Para saberlo, los mismos progenitores seguirán con atención la vida y acciones de su descendiente; pero, en el primer caso, probablemente el gerente que sembró vientos habrá dejado su puesto y otro será quien coseche tempestades.

Los negocios y las empresas son sistemas cuyas partes integrantes están interrelacionadas por tramas a veces muy complejas, que nos pueden abrumar, erosionar la confianza y el sentido de responsabilidad. Por ello, nuestras decisiones son muy importantes y constituyen la forma más directa en que un gerente o directivo crea o destruya valor. Entendiendo que todo ejecutivo «competente» es capaz de crear valor a corto plazo, ¿cuáles son los efectos de su estrategia y acciones a mediano y largo plazo? ¿Se han contemplado? ¿Se han asumido?

El pensamiento sistémico es un «lenguaje» que nos permite ver, analizar, entender y comunicar la totalidad de un sistema y la forma en que este funciona. Nos ayuda, por lo tanto, a resolver las fallas sistémicas y a intervenir exitosamente en la solución de arquetipos negativos. Nos ayuda a entender que estamos íntimamente ligados a nuestros problemas dentro del mismo sistema, que no somos agentes externos y que, en consecuencia, somos también parte de la solución, aunque la escala de contribución pueda parecer muy modesta.

Cuando reestructuramos nuestro pensamiento y lo hacemos más sistémico, aprendemos rápida e intensivamente. Los síntomas quedan solo como tales y profundizamos en busca de las reales causas de la enfermedad, visualizando la película completa y no solo una foto. Es de esta manera por la que el protagonista de El efecto mariposa descubre que la única solución pasa 
por no concentrar los beneficios en sí mismo.

Este efecto propone la hipótesis de que la velocidad y la forma como mueve las alas una mariposa, en la selva amazónica, determinan la formación o no de un huracán en el otro extremo del mundo. Los defensores de la teoría del caos piensan que el hecho de que no veamos las conexiones, no significa que no existan. Desde el punto de vista del pensamiento sistémico, en cambio, se asume que las interrelaciones existen, que pasan por nosotros, $\mathrm{y}$, por lo tanto, en alguna forma nos confieren la capacidad de cambiar los resultados.

En los negocios, se tendría mucho mayor beneficio y sostenibilidad si recordáramos siempre una frase de Albert Einstein: «Los problemas significativos no pueden ser solucionados con el mismo razonamiento que les dio origen»... Y podríamos añadir: la clave es enfrentarlos sistémicamente. 


\section{Certeza o ceguera}

Es usual que cuando la persona se incorpora a una empresa o a un nuevo puesto y pregunte con genuina curiosidad el porqué de algún proceso de trabajo, reciba una respuesta tajante: «Porque hemos determinado que es la mejor manera, por eso siempre se hace así». Desde luego, la pregunta no era ingenua. En nuestro subconsciente, por un momento, visualizamos una forma distinta de hacer las cosas, pero la respuesta, pesada como una losa, aplasta nuestras inquietudes reformistas y capitulamos pensando: «Primero tengo que aprender».

Aunque parezca dramático, esta escena podría ser una especie de versión sofisticada del experimento en el que varios simios en una jaula son bañados con agua a presión, cada vez que uno de ellos trata de alcanzar los plátanos situados en lo alto de un tubo, al medio de la jaula. Después de algunos intentos, seguidos del traumático baño, los simios golpean a cualquiera de ellos que ose subir por el tubo. Aún después de suspender el baño y reemplazar progresivamente uno a uno a todos los simios bañados o golpeados por otros nuevos, ninguno se atreve a intentar alcanzar la fruta. La paradoja radica en que ninguno de los nuevos, que propinan las golpizas, ha recibido el baño; solo ha quedado el modelo mental «nunca subas o dejes subir a otro simio por el tubo». Aun sin saber por qué lo hace.

En la jaula mental de las empresas, reprimir al nuevo gerente o 
Para poder revisar todo el contenido de esta edición, visite nuestra tienda virtual.

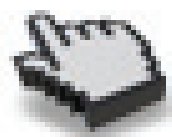

\section{(ง)}

GONZALO GALDOS

\section{Toma de decisiones}

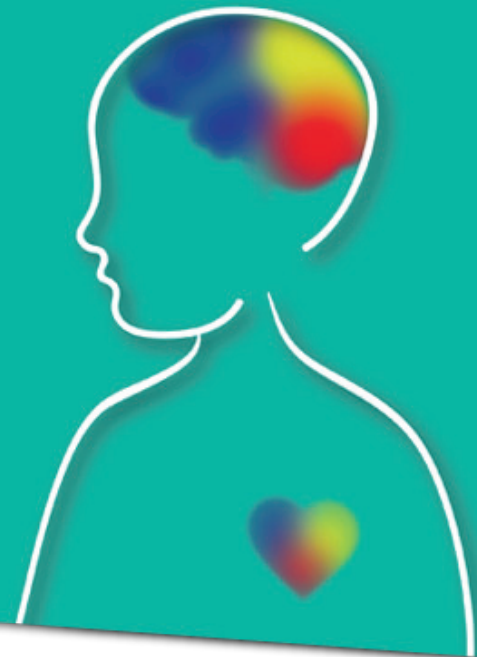

